\title{
Supraclavicular Flap for Large Anterior Chest Wall Defects-A Road Less Travelled
}

\author{
Amrita More ${ }^{1}$ Anoop Sivakumar ${ }^{1} \quad$ Gupta K Gaurav ${ }^{1}$
}

Address for correspondence Amrita More, MS, MRCS (Edin), MCh Plastic Surgery, Assistant Professor, Department of Burns, Plastic and Maxillofacial Surgery, VMMC and Safdarjung Hospital, New Delhi-110029, India (e-mail: dr.amrita47@gmail.com).

\begin{abstract}
Keywords

- pedicle flap

- upper central chest

wall reconstruction

- supraclavicular flap

Large upper central chest wall defects are a reconstructive challenge. The commonly described flaps for this area do not provide very large skin paddle, and free tissue transfer remains the only option for large skin defects. Supraclavicular flap as a local flap is widely used for head and neck reconstruction and has been described for upper chest wall defects earlier. We have used nonislanded supraclavicular flap for reconstruction of two cases of large chest wall defects, which would otherwise need free tissue transfer, single flap in one case and bilateral flaps in the other. It is easy to do and has minimal morbidity. Supraclavicular flap offers a simple solution for large skin defects of the upper central chest wall and is especially useful in patients with highoperative risk and guarded prognosis.
\end{abstract}

\section{Introduction}

Even with the advent of microsurgery and free flaps, locoregional flaps are still the workhorse flaps in the reconstruction of anterior chest wall defects, unless previous surgery or radiation has compromised the local tissues or their blood supply. Reconstructive goals include wound closure with restoration of aesthetic contours and minimization of donor site deformity. Available options are pectoralis major flaps, rectus abdominis, intercostal perforator flap, external oblique, omental flap, etc. ${ }^{1}$ For large defects, pedicle flap options are either inadequate in size, require skin graft, or are associated with significant donor site morbidity. The supraclavicular flap is a thin, fasciocutaneous flap used for head and neck reconstruction and has earlier been described for use in chest wall reconstruction..$^{2,3}$ In this series, we assess its usefulness for large upper anterior chest wall defects.

\section{Surgical Technique}

The patient was placed supine with neck turned to the contralateral side and a sandbag placed under the ipsilateral shoulder. Surface marking of external jugular vein, clavicle, and posterior border of sternocleidomastoid was done.
Supraclavicular artery origin, which lies in this triangle and course, was identified using Doppler. A rectangular flap was designed by planning in reverse and centered around the pedicle, including the skin over the clavicle, ball of shoulder and anterior deltoid fibers. The width of the flap was decided by the finger pinch test. The flap was raised from distal to proximal, including the deltoid fascia and platysma in the flap. The adhesions at the clavicle were divided sharply over the periosteum. The pedicle was visualized by transillumination in the medial third of flap. Minimal dissection was done medial to external jugular vein and above the inferior belly of omohyoid, enough only to allow flap rotation into the defect. The distal flap margin was checked for dermal bleeding, and margin trimmed until bleeding confirmed. The donor site was closed primarily after wide undermining, and dog ear in the arm was corrected by excision of extra skin., ${ }^{2,3}$

\section{Case 1}

A 26-year-old male patient presented with dermatofibrosarcoma protuberans overlying the manubrium ster-

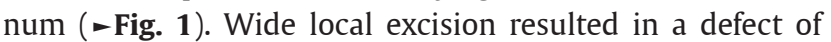
$12 \times 15 \mathrm{~cm}$, with an irregular bed and exposed sternum and 2nd rib. A $16 \times 6 \mathrm{~cm}$ right supraclavicular flap was planned published online

September 7, 2020
DOI https://doi.org/

$10.1055 / \mathrm{s}-0040-1716457$

ISSN 0970-0358. (c) 2020. Association of Plastic Surgeons of India.

This is an open access article published by Thieme under the terms of the Creative Commons Attribution-NonDerivative-NonCommercial-License, permitting copying and reproduction so long as the original work is given appropriate credit. Contents may not be used for commercial purposes, or adapted, remixed, transformed or built upon. (https://creativecommons.org/licenses/by-nc-nd/4.0/).

Thieme Medical and Scientific Publishers Pvt. Ltd. A-12, 2nd Floor, Sector 2, Noida-201301 UP, India 
with the anterior border of the flap adjoining the defect margin medially (-Figs. 2). The donor site was closed first. Initially, a bilateral flap was considered, but we managed to primarily approximate part of the left wound margin in a horizontal scar in the chest with excision of dog ear and

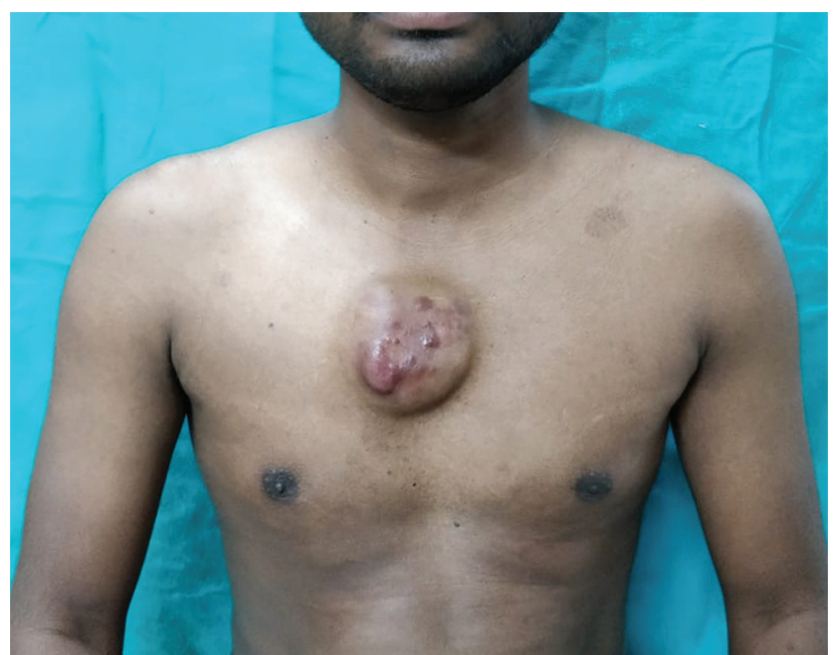

Fig. 1 Preoperative image of Case 1 showing dermatofibrosarcoma protuberans overlying manubrium sternum

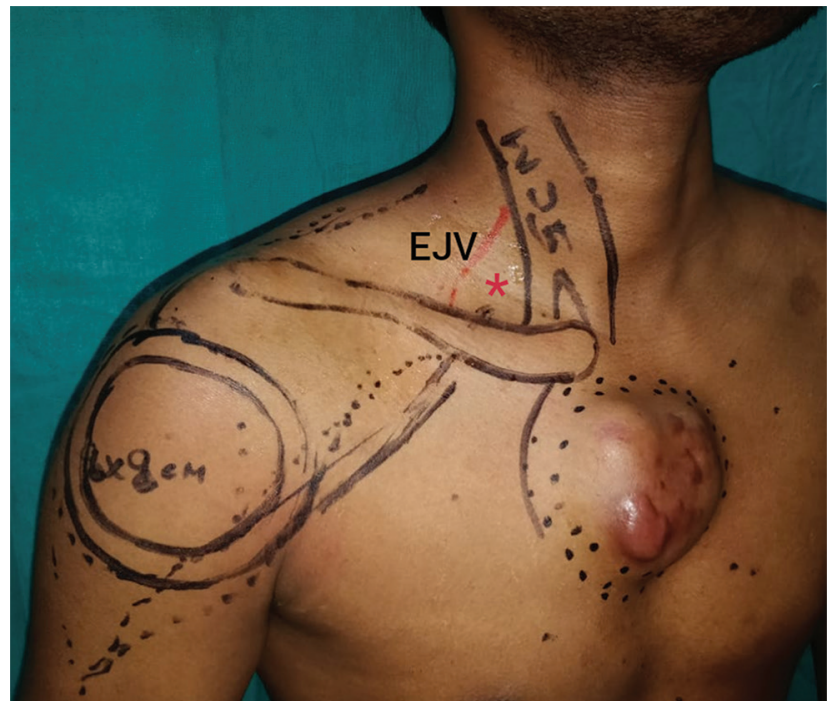

Fig. 2 Preoperative planning of island flap with surface markings of landmarks of the triangle enclosing the origin of the supraclavicular artery denoted by * later changed intraoperatively.
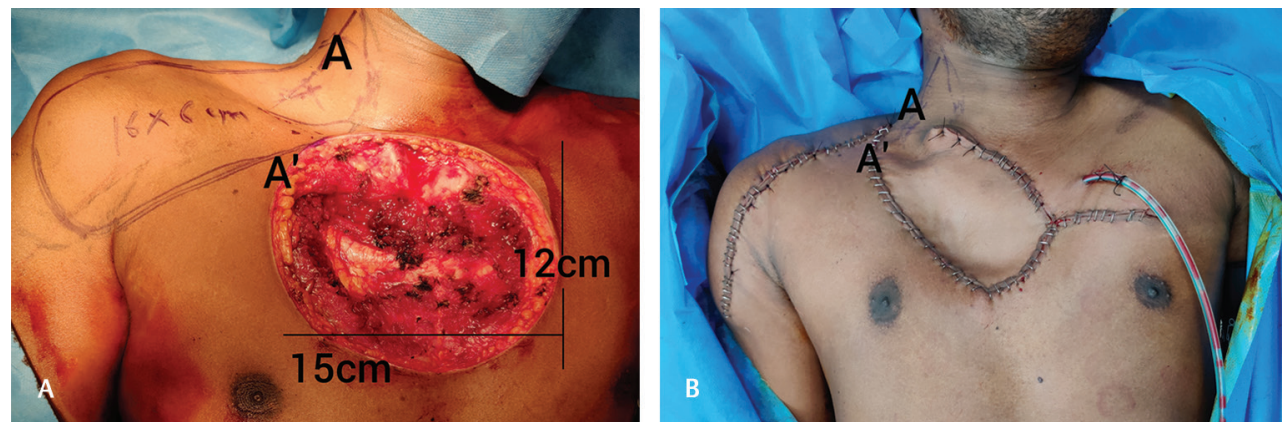

Fig. 3 (a) Postwide local excision defect of size $12 \mathrm{~cm}$ longitudinally $\times 15 \mathrm{~cm}$ transversely. Supraclavicular flap of $16 \times 6 \mathrm{~cm}$ marked. A denotes the pivot point of the flap and A' denotes the point where the flap and defect margin meet. (b) Flap after inset. Point A sutured to point A'. the flap fitted nicely in the remaining defect. Both nipples were superiorly displaced but this was symmetrical (-Figs. 3 and 4).

\section{Case 2}

A 19-year-old girl presented with a large, recurrent Ewing's sarcoma of soft tissue in the right upper chest, extending across the midline (-Fig. 5). The tumor was rapidly progressive, unresponsive to chemotherapy, and caused gross disfigurement and continuous pain. Wide local excision was performed, and a triangular defect resulted, extending from sternal notch to xiphisternum (18 cm maximum length); it had a maximum width of $24 \mathrm{~cm}$, exposing sternum, ribs, external intercostal muscle and upper pole of right breast. As the prognosis was poor and operative risk high, plan for free tissue transfer was deferred. Bilateral $15 \times 7 \mathrm{~cm}$ supraclavicular flaps were elevated. Inferior $5 \mathrm{~cm}$ of defect margins were closed primarily, and the remaining defect covered with the bilateral flaps. There was some tenting of the flap in the midline, as the flap covered the superomedial part of the right breast mound, but suction drains ensured flap adherence to the defect bed and a decent contour (-Figs. 6 and 7).

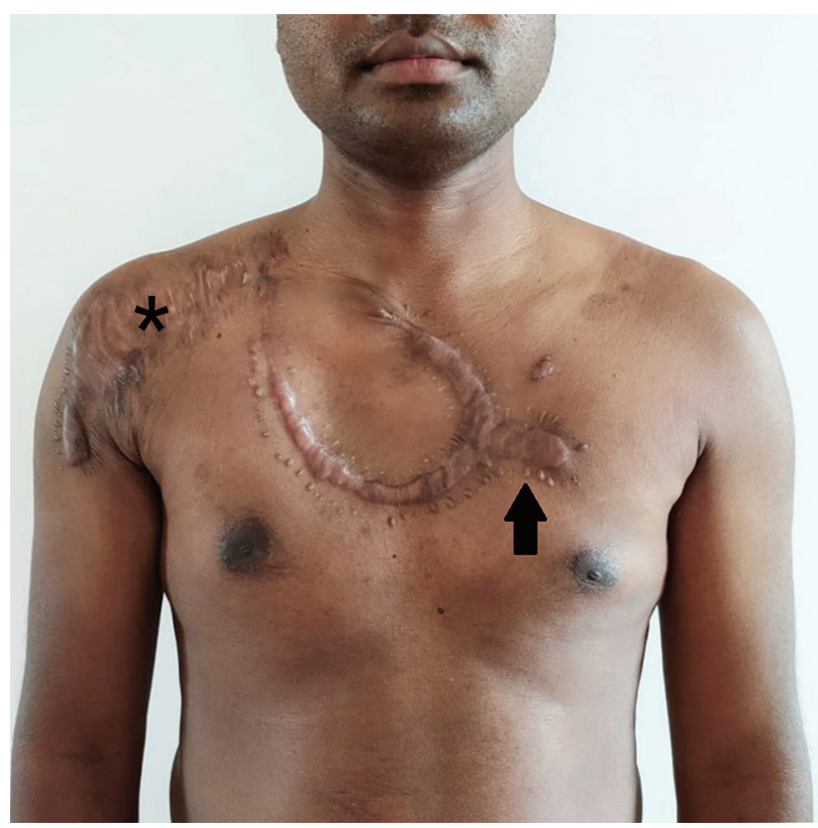

Fig. 46 months postoperative image of Case 1 showing hypertrophic (black arrow) and widened scars (asterisks). 


\section{Results}

Average time taken to raise this flap was 25 to 30 minutes. All the flaps survived completely. Postoperative recovery was uneventful. The patients were ambulatory on postop day one and discharged after drain removal within 5 days. Skin color, texture match, and contour were good. The first case was followed-up for 10 months; some scar hypertrophy in the chest and scar widening at donor site were noted ( - Fig. 4). There was no disturbance of shoulder motility or any other donor site complications in both cases. In the second case, there was a local recurrence in the 6th week, which rapidly progressed and the patient died in the 12th week postop.

\section{Discussion}

Although many flaps in this region described as "cervicohumeral flap" were in use, Cormack and Lamberty first



Fig. 5 Preoperative image of Case 2 showing large recurrent Ewing's sarcoma and overlying scar of previous surgical resection named the vessel "supraclavicular artery" in $1979 .{ }^{4}$ Due to poor knowledge of the vascular anatomy of this region and unpredictable outcomes, this flap was not in much use until the 1990s when Pallua popularized it. ${ }^{5}$ Recent cadaver dissections and perfusion studies have demonstrated this artery to be fairly constant, arising from transverse cervical artery, 6 to $8.5 \mathrm{~cm}$ from the sternoclavicular joint, and penetrating the deep fascia at 2 to $4.5 \mathrm{~cm}$ from its origin. The vessel diameter ranges from 1 to $1.5 \mathrm{~mm}$ and is accompanied by one or two veins draining into the external jugular vein or sometimes more medially. Its vascular territory extends from neck to upper chest, ball of shoulder and skin in the arm overlying anterior deltoid fibers. ${ }^{6}$ The blood supply of the flap is axial proximally and random distally demarcated by the anterior border of deltoid muscle, and the distal flap vascularity is supplemented by many small perforating vessels from the deltoid. ${ }^{7}$ Pallua has also described a more anteriorly designed flap in the deltopectoral groove and proposed to rename

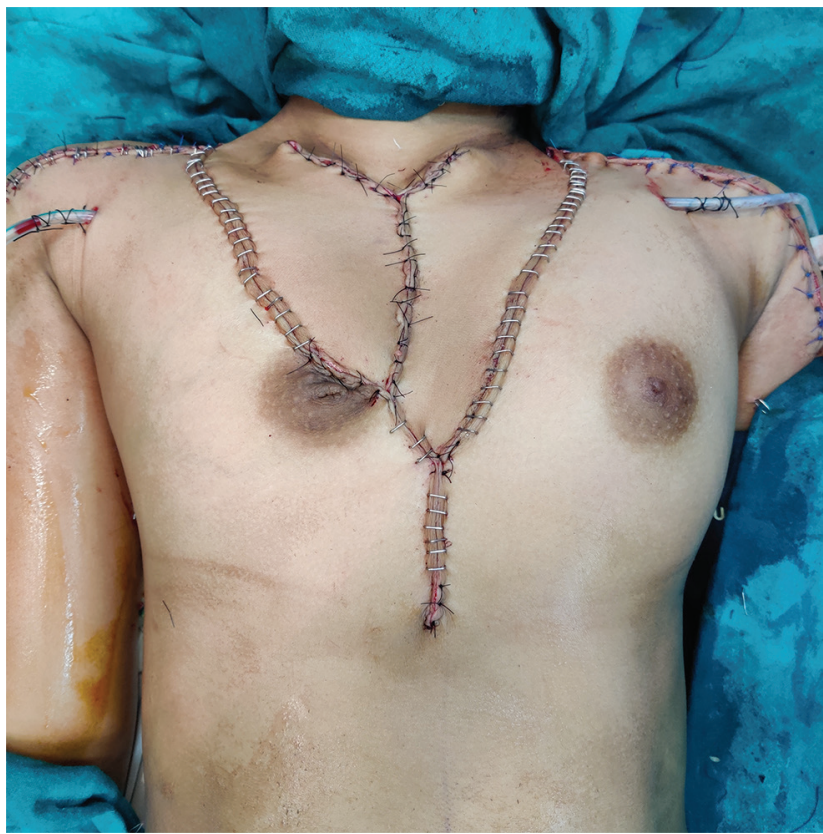

Fig. 7 Immediate postoperative image.


Fig. 6 (a) Postwide local excision defect of size $18 \mathrm{~cm}$ longitudinally $\times 24 \mathrm{~cm}$ transversely. (b) Bilateral marking of plan of $15 \times 7 \mathrm{~cm}$ supraclavicular flaps. (c) Intraoperative image showing first flap inset 
the flap as a perforator flap. ${ }^{8}$ Several authors have described flaps with lengths up to $30 \mathrm{~cm}$ and widths up to $18 \mathrm{~cm}$, but the average flap dimension described by Vinh et al. is $22 \times 10 \mathrm{~cm} .{ }^{6,8}$ Flaps wider than $10 \mathrm{~cm}$ require skin grafting of the donor site. ${ }^{6}$ This flap has been used as a pedicle flap (nonislanded, islanded, tunneled), pre-expanded or prefabricated flap, with supercharging of posterior circumflex humeral vessels, as well as a free flap. ${ }^{6,89}$ Anatomic variations of supraclavicular artery like variations in site of origin, caliber, and course have been reported but larger series report an overall good outcome with this flap and less than $5 \%$ complication rate. $6-8$

Supraclavicular flap has been used widely for both oncologic and postburn head and neck reconstruction. ${ }^{8}$ We found very few accounts of its use for chest defects, and in all cases, the defects were small and a unilateral islanded flap had been used. ${ }^{2,3}$ The defect size in both our cases were very large and wider than manageable, with vertical rectus abdominis flap or internal mammary artery perforator flap. We considered pectoralis major flap in Case 1: muscle flap with grafting would have involved taking bilateral flaps and extensive muscle dissection and morbidity; pectoralis major myocutaneous flap for this defect size would have required grafting of donor site and poor cosmesis. Our alternate plans were free tissue transfer and greater omentum flap with skin grafting, both associated with significantly longer operative time and higher morbidity.

Supraclavicular flap is a thin and pliable flap and provides good color and texture match for adjacent head, neck and chest area defects. For defects that need more than 90 degree of rotation, flap needs to be islanded to enable rotation and avoid dog ear. We used nonislanded flaps that required no pedicle dissection, took less than half an hour to raise, and the technique was as needed to raise any other fasciocutaneous flap. Significant undermining of adjacent skin was needed to close donor site, and upper chest skin had to be pulled into the neck. This came to be an advantage in our cases, as it reduced the longitudinal dimension of the defect, and we were able to cover defects reaching up to the fourth intercostal space easily while staying in the safe territory of this flap.

The known complications of the flaps include distal flap necrosis, seroma, hematoma, scar complications, and shoulder dysfunction. Flap necrosis can occur if flap is too long, pedicle is injured or compressed, or in anatomical variations. ${ }^{6}$ While most authors only performed a preoperative Doppler study, few authors also performed CT angiography in each case, especially when planning free tissue transfer. ${ }^{10}$ Shoulder dysfunction is rare. The only drawback of this flap is hypertrophic scarring and widening of scars, especially in thin, young patients with tight skin and patients with keloid tendencies.

\section{Conclusion}

Supraclavicular flap is a reliable and a versatile flap. It is easy to perform, has minimal morbidity, and gives good color and texture match as well as a well-concealed donor scar. Supraclavicular flap should be a part of the surgeon's armamentarium for upper central chest wall reconstruction, which offers a simple solution especially in high-risk patients.

Funding

None.

\section{Conflicts of Interest}

None declared.

\section{Acknowledgments}

None.

\section{References}

1 Kua EHJ, Chia HL, Goh TLH, et al. A general algorithm for chest wall reconstruction based on a retrospective review. Eur J Plast Surg 2015;38:211-220

2 Pallua N, Magnus Noah E. The tunneled supraclavicular island flap: an optimized technique for head and neck reconstruction. Plast Reconstr Surg 2000;105(3):842-851, discussion 852-854

3 Telang P, Jagannathan M, Devale M. A study of the use of the supraclavicular artery flap for resurfacing of head, neck, and upper torso defects. Indian J Plast Surg 2009;42(1):4-12

4 Lamberty BG. The supra-clavicular axial patterned flap. Br J Plast Surg 1979;32(3):207-212

5 Pallua N, Machens HG, Rennekampff O, Becker M, Berger A. The fasciocutaneous supraclavicular artery island flap for releasing postburn mentosternal contractures. Plast Reconstr Surg 1997;99(7):1878-1884, discussion 1885-1886

6 Vinh VQ, Van Anh T, Ogawa R, Hyakusoku H. Anatomical and clinical studies of the supraclavicular flap: analysis of 103 flaps used to reconstruct neck scar contractures. Plast Reconstr Surg 2009;123(5):1471-1480

7 Ross RJ, Baillieu CE, Shayan R, Leung M, Ashton MW. The anatomical basis for improving the reliability of the supraclavicular flap. J Plast Reconstr Aesthet Surg 2014;67(2):198-204

8 Pallua N, Wolter TP. Moving forwards: the anterior supraclavicular artery perforator (a-SAP) flap: a new pedicled or free perforator flap based on the anterior supraclavicular vessels. J Plast Reconstr Aesthet Surg 2013;66(4):489-496

9 Alves HRN, de Faria JCM, Busnardo F, et al. Forehead reconstruction using supraclavicular flap with microsurgical technique: Free flap and a pedicle supercharged flap. JPRAS Open 2017;14:33-38

10 Adams AS, Wright MJ, Johnston S, et al. The use of multislice CT angiography preoperative study for supraclavicular artery island flap harvesting. Ann Plast Surg 2012;69(3):312-315 